\title{
AN RGD-RESTRICTED SUBSTRATE INTERFACE IS SUFFICIENT FOR THE ADHESION, GROWTH AND CARTILAGE FORMING CAPACITY OF HUMAN CHONDROCYTES
}

\author{
Daniel Vonwil ${ }^{1}$, Martin Schuler ${ }^{2}$, Andrea Barbero ${ }^{1}$, Simon Ströbel ${ }^{1}$, David Wendt ${ }^{1}$, \\ Marcus Textor ${ }^{3}$, Ueli Aebi ${ }^{4}$, and Ivan Martin ${ }^{1}$ \\ ${ }^{1}$ Departments of Surgery and of Biomedicine, University Hospital Basel, Basel \\ ${ }^{2}$ Institute Straumann AG, Basel \\ ${ }^{3}$ Laboratory for Surface Science and Technology, ETH Zurich, Zurich \\ ${ }^{4}$ ME Müller Institute for Structural Biology, University of Basel, Basel, Switzerland
}

\begin{abstract}
This study aimed at testing whether an RGD-restricted substrate interface is sufficient for adhesion and growth of human articular chondrocytes (HAC), and whether it enhances their post expansion chondrogenic capacity. HAC/ substrate interaction was restricted to RGD by modifying tissue culture polystyrene (TCPS) with a poly(ethylene glycol) (PEG) based copolymer system that renders the surface resistant to protein adsorption while at the same time presenting the bioactive RGD-containing peptide GCRGYGRGDSPG (RGD). As compared to TCPS, HAC cultured on RGD spread faster (1.9-fold), maintained higher type II collagen mRNA expression (4.9-fold) and displayed a $19 \%$ lower spreading area. On RGD, HAC attachment efficiency $(66 \pm 10 \%)$ and proliferation rate $(0.56 \pm 0.04$ doublings/day), as well as type II collagen mRNA expression in the subsequent chondrogenic differentiation phase, were similar to those of cells cultured on TCPS. In contrast, cartilaginous matrix deposition by HAC expanded on $R G D$ was slightly but consistently higher ( $15 \%$ higher glycosaminoglycan-to-DNA ratio). $R D G$ (bioinactive peptide) and $P E G$ (no peptide ligand) controls yielded drastically reduced attachment efficiency (lower than 11\%) and proliferation (lower than 0.20 doublings/day). Collectively, these data indicate that restriction of HAC interaction with a substrate through RGD peptides is sufficient to support their adhesion, growth and maintenance of cartilage forming capacity. The concept could thus be implemented in materials for cartilage repair, whereby in situ recruited/infiltrated chondroprogenitor cells would proliferate while maintaining their ability to differentiate and generate cartilage tissue.
\end{abstract}

Keywords: Biomimetics, cartilage repair, cartilage differentiation, cell motility, cell proliferation.

*Address for correspondence:

Ivan Martin,

Institute for Surgical Research and Hospital Management, University Hospital Basel,

Hebelstrasse 20,

CH-4031 Basel, Switzerland

Telephone Number: $+41(0) 612652384$

FAX Number: +41(0)61 2653990

E-mail: imartin@uhbs.ch
Introduction

During human articular chondrocyte (HAC) expansion, as it is typically performed prior to autologous chondrocyte implantation (ACI) (Brittberg, 2008), HAC dedifferentiate and their re-differentiation capacity is often limited (Benya and Shaffer, 1982; Darling and Athanasiou, 2005). De-differentiation of chondrocytes manifests by cell morphological transition from round to fibroblastlike, the loss of large proteoglycans (e.g., aggrecan) and type II collagen production (Stockdale et al., 1963; Marlovits et al., 2004), and the switch to synthesis of type I collagen, fibronectin (FN), and small noncartilaginous proteoglycans (Aulthouse et al., 1989; Marlovits et al., 2004). This raises the issue that subsequent to expansion the de-differentiated chondrocytes have the propensity to produce fibrocartilaginous tissue, which is of inferior mechanical quality as compared to hyaline cartilage.

The biology of chondrocytes is highly influenced by interactions with specific extracellular matrix (ECM) molecules (Scully et al., 2001; van der Kraan et al., 2002). Thus, targeted modification of cell culture substrates with biological motives has the potential to improve HAC expansion strategies. A typical approach to investigate substrate effects on chondrocyte phenotype has been to coat tissue culture treated polystyrene (TCPS; gas plasma activated polystyrene) with specific ECM-proteins. TCPS, the current gold standard substrate for HAC monolayer expansion, readily adsorbs proteins present in serum containing culture medium and thereby rapidly forms a proteinaceous adlayer that determines subsequent cellsurface interactions (Horbett, 1986).

It was found that compared to a bare plastic substrate, chicken epiphysial chondrocytes longer retained their native morphology on plastic precoated with type II collagen (Shakibei et al., 1997), and rabbit articular chondrocytes better preserved their phenotype on type I collagen (Kino-Oka et al., 2005). In contrast, other studies showed that the expression of type I and II collagen by chondrocytes was not altered in response to substrates coated with either type I or II collagen or fibronectin (Brodkin et al., 2004; Barbero et al., 2006). The controversial results could at least partially be due to the fact that simple application of natural protein layers lacks control over the presentation of active ligands to the cells (Mrksich, 2002). In fact, protein adsorption is generally governed by electrostatic interactions, van der Waals 
forces and short range repulsion forces and occurs randomly in various different orientations of the protein (Talbot et al., 2000). Also, it has been demonstrated on a variety of surfaces including TCPS that adsorption can induce conformational changes in several different proteins as for example in collagen and results in alteration of the native protein biological activity (for review see (Nakanishi et al., 2001)). Thus, the nature of such interfaces is highly complex with regard to composition and conformation of the adsorbed proteins (Koenig et al., 2003).

The uncertainties introduced by working with natural protein layers has driven the development and synthesis of materials which provide full control over the ligandreceptor interactions (Hubbell, 1999), not only for optimizing cell culture labware but also for the development of smart materials in regenerative medicine. To this end, RGD grafted poly-L-lysine-graftpoly(ethylene glycol) (PLL-g-PEG) copolymers offer an elegant solution to block non-specific protein adsorption from serum through their PEG compartment, while introducing biofunctionality via PEG chains grafted with a peptide that contains the cell adhesion sequence RGD (VandeVondele et al., 2003, for a schematic depiction see Fig. 1).

The peptide sequence RGD is present in several ECMproteins like fibronectin, collagens and vitronectin and not only serves as the minimal requirement for integrinmediated cell anchoring (Ruoslahti, 1996), but also stimulates integrin signalling which can modulate chondrocyte morphology, motility, proliferation and differentiation. Mice with a cartilage specific deletion of beta 1 integrins have abnormally shaped chondrocytes that fail to arrange into columns within the growth plate and show a decreased proliferation rate (Aszodi et al., 2003). In the developing mouse zeugopod, it was even shown that blocking $\alpha 5 \beta 1$ integrin interaction with RGD from the ECM inhibits pre-hypertrophic chondrocyte differentiation and eventually leads to apoptosis (Garciadiego-Cázares et al., 2004).

A variety of materials has been modified with RGDpeptides. Their in vitro biological effect has been tested often using cell lines of animal origin (for review see (Hersel et al., 2003)) and only few studies were done with chondrocytes. Moreover, two studies (published by one and the same group) reported contradicting findings about the influence of RGD-peptide modified materials on chondrocyte proliferation and matrix production (Hsu et al., 2004; Hsu et al., 2006). This may either be attributed to the difference between the species from which the chondrocytes were derived (porcine or rabbit respectively), or to the fact that the cell/substrate-interaction was not restricted to RGD. In fact, RGD was presented in different blends with other components (i.e., type II collagen and chitosan), which per se also mediated considerable cell adhesion. RGD-peptide coated materials were tested also for culture of HAC (Jeschke et al., 2002), although the study was limited to analysis of attachment and integrin expression.

The level of control over cell/substrate interaction as it is provided by RGD grafted PLL- $g$-PEG is necessary to investigate the direct and specific effect of the RGD ligand

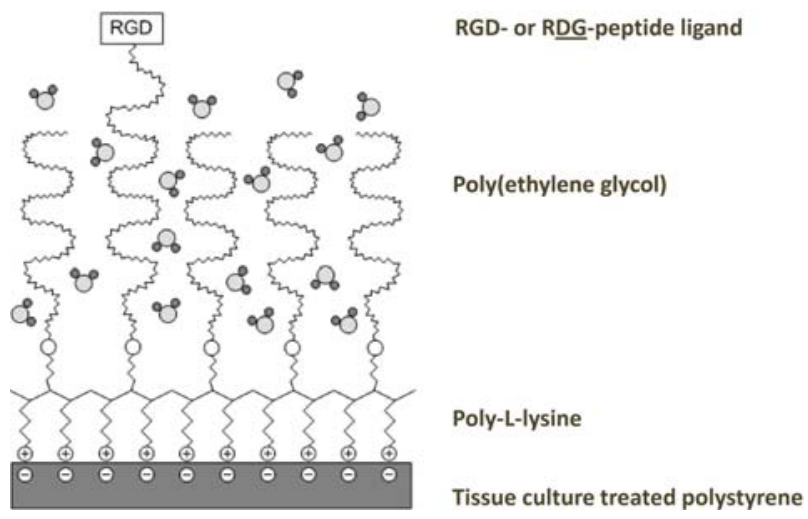

Fig. 1: Schematic depiction of RGD-grafted PLL-gPEG. The grafted copolymer adsorbs from dilute aqueous solutions onto negatively charged tissue culture treated polystyrene (TCPS) via the positively charged poly-L-lysine (PLL) backbone. While the poly(ethylene glycol) (PEG) side chains render the surface resistant to protein adsorption, a fraction of the grafted PEG is functionalized with an RGD containing cell adhesion peptide. Alternatively, a bioinactive, scrambled variant RDG was used for negative controls.

on cell behaviour. This copolymer has been assessed for its effect on attachment, morphology and proliferation of different cells including human fibroblasts \& epithelial cells as well as rat osteoblasts, \& cardiomyocytes (Schuler et al., 2009a; VandeVondele et al., 2003; Franks et al., 2007). Moreover, RGD grafted PLL- $g$-PEG showed to reduce differentiation in osteoblast-like cells (human osteosarcoma cell line) (Tosatti et al., 2004). Yet, no study has assessed primary human articular chondrocyte culture on such an RGD-restricted substrate.

In this work, we tested whether an RGD-restricted substrate interface is sufficient to allow for HAC adhesion, growth and maintenance of the chondrogenic capacity. In particular, HAC attachment, spreading kinetics, morphology, proliferation and gene expression were assessed on a poly(ethylene glycol) (PEG) based copolymer system that renders the surface resistant to protein adsorption while at the same time presenting the bioactive, RGD-containing peptide GCRGYGRGDSPG (RGD) (Pasche et al., 2005; VandeVondele et al., 2003; Schuler et al., 2006b). HAC culture on RGD was compared to that on tissue culture treated polystyrene (TCPS, standard substrate) and on control PEG substrates, without or with the scrambled sequence $R D G$. The post-expansion cartilage formation by expanded HAC was tested in a standard chondrogenic assay.

\section{Materials \& Methods}

\section{Polymer synthesis and characterization}

Peptide-functionalized and non-functionalized PLL- $g$ PEG polymers were synthesized and characterized as previously published (Schuler et al., 2006a; Schuler et al., 2009a, for a schematic depiction of the copolymer see 
Fig. 1). In brief, these polymers are based on a PLL backbone of approximately 120 L-lysine units (average value in view of the polydispersity of 1.4 of the polymer; Sigma-Aldrich, Buchs, Switzerland), a PEG side chain of approximately 47 ethylene glycol units (PEG MW $2 \mathrm{kDa}$, polydispersity: 1.02; Nektar, Bradford, UK) and a grafting ratio $(g)$ between 3.3 and 4.6, expressed as the number of lysine monomers per PEG side chain. A vinyl sulfonemodified PEG chain of $3.4 \mathrm{kDa}$ molecular weight (polydispersity: 1.01; Nektar) was used to couple the peptide sequences with the PLL backbone. The following peptides were used for the synthesis of functionalized PLL$g$-PEG polymers: the bioactive RGD-containing N-acetylGCRGYGRGDSPG-amide and the scrambled (bioinactive) N-acetyl-GCRGYGRDGSPG-amide (both purchased from Jerini, Berlin, Germany). Polymer architectures (grafting ratios and fractions of peptidefunctionalization) were determined with nuclear magnetic resonance spectroscopy (NMR) whereas adsorbed polymer and serum masses were measured using optical waveguide lightmode spectroscopy (OWLS) (see Table 1 for details). All polymers used were proven to be highly resistant to non-specific serum adsorption $\left(<5 \mathrm{ng} / \mathrm{cm}^{2}\right)$.

\section{Surface modification for cell culture}

For modifying the surface of tissue culture treated polystyrene (TCPS; atmospheric gas plasma treated polystyrene), frozen samples of dehydrated PLL- $g$-PEG polymer powders were warmed up to room temperature, dissolved in a salt buffer solution (denoted hereafter as HEPES2) containing $10 \mathrm{mM}$ HEPES and $150 \mathrm{mM} \mathrm{NaCl}$ at pH 7.4 (to reach a final concentration of $0.5 \mathrm{mg} / \mathrm{ml}$ ) and filter sterilized ( $0.22 \mu \mathrm{m}$ filter, Milian, Basel, Switzerland). TCPS wells/dishes (TPP, Trasdingen, Switzerland) and Thermanox ${ }^{\circledR}$ lamellae (Nunc, Roskilde, Denmark for CLSM, activated with a UVO-Cleaner (Model 42-220, Jetlight Company, USA)) were coated at room temperature for $45 \mathrm{~min}$ with $100 \mathrm{ml} / \mathrm{cm}^{2}$ of the above described polymer solutions while stirring on an orbital shaker. Supernatant polymer solution was aspirated and surfaces were washed twice with $200 \mu \mathrm{l} / \mathrm{cm}^{2}$ HEPES2 buffer solution for $5 \mathrm{~min}$. For convenience, PEGylated surfaces will be named

Table 1: Molecular weight, grafting ratio, peptide functionalization, polymer/protein adsorption and peptide surface density for all polymers used in this paper. ${ }^{a}$ measured with NMR technique. ${ }^{b}$ measured with OWLS technique. ${ }^{\mathrm{c}}$ see (Schuler, et al., 2006a) for details.

\begin{tabular}{lccc}
\hline & PEG & RGD & RDG \\
\hline Molecular weight PLL $[\mathrm{kDa}]$ & 15.9 & 15.9 & 15.9 \\
Molecular weight lysine unit $[\mathrm{kDa}]$ & 0.128 & 0.128 & 0.128 \\
Molecular weight peptide $[\mathrm{kDa}]$ & - & 1.222 & 1.222 \\
Molecular weight entire polymer $[\mathrm{kDa}]$ & 91.1 & 52.8 & 56.8 \\
Grafting ratio $g[-]^{\mathrm{a}}$ & 3.3 & 7 & 6.4 \\
Peptide-functionalized PEG-chains $[\%]^{\mathrm{a}}$ & - & 3.4 & 3.7 \\
Polymer adsorption $\left[\mathrm{ng} / \mathrm{cm}^{2}\right]^{\mathrm{b}}$ & 150 & 143 & 135 \\
Protein adsorption $\left[\mathrm{ng} / \mathrm{cm}^{2}\right]^{\mathrm{b}}$ & $<5$ & $<5$ & $<5$ \\
Peptide surface density $\rho_{\mathrm{ps}}\left[\mathrm{pmol} / \mathrm{cm}^{2}\right]^{\mathrm{c}}$ & - & 1.6 & 1.7 \\
\hline
\end{tabular}

hereafter according to their peptide sequences (PLL- $g$ PEG/PEG-RGD as RGD and PLL- $g$-PEG/PEG-RDG as $R \underline{D G}$ ) whereas the non-functionalized PLL- $g$-PEG surface will be denoted PEG.

\section{Cell isolation and expansion}

Full thickness human articular cartilage samples were collected within 24 hours post mortem from the femoral lateral condyle of three different donors (age in years; A:53, B:62, C:66), with no history of joint disease, after obtained informed consent, following protocol approval by the local ethical committee (No. 78/07). HAC were isolated upon 22 hour incubation at $37^{\circ} \mathrm{C}$ in $0.15 \%$ type II collagenase and resuspended with Dulbecco's modified Eagle's medium (DMEM) containing $4.5 \mathrm{mg} / \mathrm{ml} \mathrm{D}$-glucose, 0.1 $\mathrm{mM}$ non-essential amino acids, $1 \mathrm{mM}$ sodium pyruvate, $10 \mathrm{mM}$ HEPES buffer, $100 \mathrm{U} / \mathrm{ml}$ penicillin, $100 \mu \mathrm{g} / \mathrm{ml}$ streptomycin, and $0.29 \mathrm{mg} / \mathrm{ml} \mathrm{L}$-glutamine, supplemented with 10\% FBS (all from Gibco, Paisley, UK) (complete medium, CM). For the first expansion phase, HAC from each donor were seeded onto either TCPS, RGD, RDG or $P E G$ substrates at a concentration of $10^{4}$ cells $/ \mathrm{cm}^{2}$ in a $8.96 \mathrm{~cm}^{2}$ well (six well- plate). HAC were cultured in CM supplemented with $1 \mathrm{ng} / \mathrm{ml}$ TGF- $\beta 1,5 \mathrm{ng} / \mathrm{ml} \mathrm{FGF-2,} 10$ $\mathrm{ng} / \mathrm{ml}$ PDGF-BB (expansion medium, all from R\&D, Minneapolis, $\mathrm{MN}, \mathrm{USA}$ ) in a humidified $37^{\circ} \mathrm{C} / 5 \% \mathrm{CO}_{2}$ incubator. These specific growth factors have previously been shown to enhance HAC proliferation and postexpansion re-differentiation capacity (Barbero et al., 2004). After 7 days of expansion, HAC grew confluent (passage 1) and were detached by a treatment with $0.3 \%$ type II collagenase, followed by $0.05 \%$ trypsin $/ 0.52 \mathrm{mM}$ EDTA (Gibco), re-plated on the corresponding surfaces at a density of $5 \times 10^{3}$ cells $/ \mathrm{cm}^{2}$ in a $60.1 \mathrm{~cm}^{2}$ Petri dish for the second expansion step. Reaching confluency again after another 7 days (passage 2), HAC were detached and assessed for their chondrogenic re-differentiation capacity, morphology and mRNA expression.

\section{Cell attachment and proliferation}

To determine HAC attachment 24 hours after seeding in expansion medium, supernatants containing non-adherent HAC were collected, counted in a Neumann chamber and their viability was assessed using trypan blue (Sigma Chemicals, St. Louis, MO, USA). The non-adherent HAC from $R \underline{D G}$ and $P E G$ were returned to the corresponding dishes at each medium change. Cell proliferation rate was calculated as the ratio of $\log _{2}\left(\mathrm{~N} / \mathrm{N}_{0}\right)$ to $\mathrm{T}$, where $\mathrm{N}_{0}$ and $\mathrm{N}$ are the numbers of cells respectively at the beginning (number of seeded HAC) and the end (number of harvested $\mathrm{HAC}$ ) of the expansion phase, and $\mathrm{T}$ is the time (days) required for the expansion (Barbero et al., 2004).

\section{Cell morphology}

HAC after the second confluency on TCPS or RGD were detached, reseeded onto a correspondingly coated lamellae at a density of $5 \times 10^{3}$ cells $/ \mathrm{cm}^{2}$ and cultured in expansion medium in a humidified $37^{\circ} \mathrm{C} / 5 \% \mathrm{CO}_{2}$ incubator for three days. The lamellae were then rinsed with PBS (Gibco). Rinsed HAC were fixed with $1 \%$ glutaraldehyde in phosphate buffered saline (PBS) for $30 \mathrm{~min}$ at room 
temperature. Substrates were rinsed with PBS before permeabilising and further fixing with $2 \%$ Octylpolyethylene (Octyl-POE) and $0.125 \%$ glutaraldehyde for 5 min. Following a PBS wash, residual glutaraldehyde was reduced with a solution of $0.5 \mathrm{~g} / \mathrm{ml} \mathrm{NaBH}_{4}$ in $\mathrm{PBS}$ at $0^{\circ} \mathrm{C}$ for $20 \mathrm{~min}$. After washing with PBS again, HAC were labelled with TRITC-phalloidin 1:900 $\left(\lambda_{\mathrm{Ex}}=488 \mathrm{~nm}\right.$, Sigma Chemicals) against actin filaments and DRAQ5 1:200 $\left(\lambda_{\mathrm{Ex}}=647 \mathrm{~nm}\right.$, Alexis Biochemicals) to label DNA in the nuclei (all dilutions in PBS). Finally, the lamella were mounted onto a glass slide using mowiol-1188 (Hoechst, Frankfurt, Germany) containing $0.75 \%$ of the anti-fading agent N-propyl-gallate (Sigma Chemicals) and stored at $4^{\circ} \mathrm{C}$ in the dark. Fluorescence images were acquired with a Leica TCS SP CLSM, using a 63x HC PL APO immersion objective. The number of stacks was fixed to 20 , while each stack $\left(1024 \times 1024\right.$ pixel $\left.^{2}\right)$ was scanned at medium speed and averaged four times.

To describe the HAC morphology and the degree of spreading, a cell shape factor $\phi$ (Eqn. 1) was used (Schuler et al., 2006a; Schuler et al., 2009b).

$$
\phi=\frac{4 \pi \mathrm{A}}{\mathrm{p}^{2}}
$$

The area $A$ and the perimeter $p$ required for calculating the shape factor $\phi$ were determined from the CLSM images using Image J version 1.37 (Rasband, 2009). A shape factor for a round cell can assume values near to one. Circles have the greatest area-to perimeter ratio and their shape factor $\phi$ is 1 , whereas a thin, thread-like object would have a shape factor $\phi$ near zero (see Fig. 5B).

\section{Initial cell spreading, kinetics \& motility}

Time lapse microscopy experiments were performed on an Olympus (Tokyo, Japan) IX81 motorized, inverted microscope in phase contrast mode, using a 10x LCPFL objective combined with a 1.6x magnifying lens (to investigate initial spreading) or an UplanApo 4x objective (to investigate motility). The microscopes were equipped with a high resolution position controller to drive the motorized stage. HAC were seeded onto either TCPS or $R G D$ in expansion medium at a density of $10^{4}$ cells $/ \mathrm{cm}^{2}$ (for studies on initial spreading) or $7.5 \times 10^{3}$ cells $/ \mathrm{cm}^{2}$ (for studies on motility) and kept in a box at $37^{\circ} \mathrm{C} / 5 \% \mathrm{CO}_{2}$. The initial spreading kinetic of HAC from Donor $\mathrm{C}$ was followed for 18 minutes. Starting 5 minutes post seeding, every two minutes an image was acquired from 15 randomly selected areas of each substrate. Using Image J, the spreading kinetic of 28 cells, which were at the onset of spreading, was determined on each surface based on the spreading area.

\section{Chondrogenic assay}

The chondrogenic capacity of HAC expanded on either TCPS or RGD was investigated in pellet culture using a chemically defined, serum-free medium (SFM), which consists of DMEM containing $4.5 \mathrm{mg} / \mathrm{ml} \mathrm{D}$-glucose, 0.1 $\mathrm{mM}$ non-essential amino acids, $1 \mathrm{mM}$ sodium pyruvate, $10 \mathrm{mM}$ HEPES buffer, $100 \mathrm{U} / \mathrm{ml}$ penicillin, $100 \mu \mathrm{g} / \mathrm{ml}$ streptomycin, and $0.29 \mathrm{mg} / \mathrm{ml} \mathrm{L}$-glutamine (all Gibco) supplemented with ITS $^{+1}(10 \mu \mathrm{g} / \mathrm{ml}$ insulin, $5.5 \mathrm{mg} / \mathrm{ml}$ transferrin, $5 \mathrm{ng} / \mathrm{ml}$ selenium, $0.5 \mathrm{mg} / \mathrm{ml}$ bovine serum albumin, $4.7 \mathrm{mg} / \mathrm{ml}$ linoleic acid), $1.25 \mathrm{mg} / \mathrm{ml}$ human serum albumin, $0.1 \mathrm{mM}$ ascorbic acid 2-phosphate and $10^{-7} \mathrm{M}$ dexamethasone (all Sigma Chemicals, USA) and $10 \mathrm{ng} / \mathrm{ml}$ TGF- $\beta 1$ (R\&D, UK) (chondrogenic medium) (Barbero et al., 2003; Jakob et al., 2001). Aliquots of $5 \times 10^{5}$ $\mathrm{HAC} / 0.5 \mathrm{ml}$ were centrifuged at $250 \mathrm{~g}$ for $5 \mathrm{~min}$ in $1.5 \mathrm{ml}$ polypropylene conical tubes (Saarstedt, Nümbrecht, Germany) to form spherical pellets, which were placed onto a 3D orbital shaker (Bioblock Scientific, Frenkendorf, Switzerland) at $30 \mathrm{rpm}$. Pellets were cultured for 2 weeks at $37^{\circ} \mathrm{C} / 5 \% \mathrm{CO}_{2}$, with medium changes twice per week, and subsequently processed for histological, immunohistochemical, biochemical and mRNA analysis.

\section{Gene expression analysis}

Total RNA of cells was extracted using Trizol (Life Technologies, Basel, Switzerland) and the standard singlestep acid-phenol guanidinium method. RNA was treated with DNAseI using the DNA-free ${ }^{\mathrm{TM}}$ Kit (Ambion, Applied Biosystems, Carlsbad, CA, USA) and quantified spectrometrically. cDNA was generated from $3 \mu \mathrm{g}$ of RNA by using $500 \mu \mathrm{g} / \mathrm{ml}$ random hexamers (Catalys AG, Wallisellen, Switzerland) and $1 \mu \mathrm{l}$ of $50 \mathrm{U} / \mathrm{ml}$ Stratascript ${ }^{\mathrm{TM}}$ reverse transcriptase (Stratagene, Agilent Technologies, Basel, Switzerland), in the presence of dNTPs. Real-time RT-PCR reactions were performed and monitored using the ABI Prism 7700 Sequence Detection System (PerkinElmer/Applied Biosystems, Rotkreuz, Switzerland). After

Table 2: Description of the designed primers and probes for real-time RT-PCR.

\begin{tabular}{|c|c|c|c|c|}
\hline Gene & Forward and reverse primers $\left(5^{\prime} \rightarrow 3^{\prime}\right)$ & $\begin{array}{c}\text { Primer } \\
\text { Concentration } \\
n M \\
\end{array}$ & Probe $\left(5^{\prime} \rightarrow 3^{\prime}\right)$ & $\begin{array}{c}\text { Probe } \\
\text { Concentration } \\
n M \\
\end{array}$ \\
\hline 18S rRNA & $\begin{array}{l}\text { CGGCTACCACATCCAAGGAA } \\
\text { GCTGGAATTACCGCGGCT }\end{array}$ & 26 & TGCTGGCACCAGACTTGCCCTC & 50 \\
\hline Type I collagen & $\begin{array}{l}\text { TTTTGTATTCAATCACTGTCTTGCC } \\
\text { CAGCCGCTTCACCTACAGC }\end{array}$ & 300 & CCGGTGTGACTCGTGCAGCCATC & 100 \\
\hline Type II collagen & $\begin{array}{l}\text { GGCAATAGCAGGTTCACGTACA } \\
\text { CGATAACAGTCTTGCCCCACTT }\end{array}$ & 900 & CCGGTATGTTTCGTGCAGCCATCCT & 200 \\
\hline Type X collagen & $\begin{array}{l}\text { CAAGGCACCATCTCCAGGAA } \\
\text { AAAGGGTATTTGTGGCAGCATATT }\end{array}$ & 900 & TCCAGCACGCAGAATCCATCTGA & 200 \\
\hline
\end{tabular}




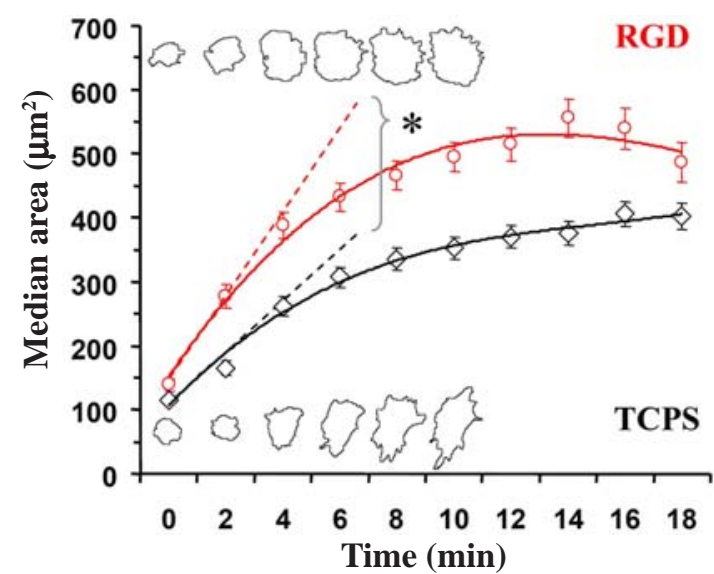

Fig.2: Initial spreading of human articular chondrocytes (HAC) on tissue culture polystyrene (TCPS, black diamonds) and on RGD-functionalized PLL-g-PEG (RGD, red circles). Immediately after seeding onto the corresponding surface, the spreading kinetic of HAC in expansion medium was followed by time lapse phase contrast microscopy every two min during $18 \mathrm{~min}$. Spreading was measured as footprint area $(n=28$ for each surface; HAC from Donor $\mathrm{C}$ as a representative example) and reported as median value in $\mu^{2}$. The dashed tangential lines indicate the maximal slope mmax which was significantly different on the two substrates $\left(\mathrm{n}=28\right.$, asterisk indicates $p=3.4 \times 10^{-5}$; Utest Mann-Whitney, two tailed). Cell outlines at each time point (up to minute 10) visualize an example HAC from each surface (RGD: upper row; TCPS: lower row) which matches with the indicated solid trend line ( $3^{\text {rd }}$ order polynomial fit, $\mathrm{R}^{2} \geq 0.99$ ). Error bars represent the standard error.

an initial denaturation at $95^{\circ} \mathrm{C}$ for $10 \mathrm{~min}$, the cDNA products were amplified with $45 \mathrm{PCR}$ cycles, consisting of a denaturation step at $95^{\circ} \mathrm{C}$ for $15 \mathrm{~s}$ and an extension step at $60^{\circ} \mathrm{C}$ for $1 \mathrm{~min}$. Sequences and concentrations of primers and probes were used as indicated in Table 2.

For each sample, the threshold cycle $(\mathrm{Ct})$ value was determined as the cycle number at which the fluorescence intensity reached 0.05 . For each cDNA sample, the value of $18 \mathrm{~S}$ was subtracted from the $\mathrm{Ct}$ value of the target gene, to derive $\Delta \mathrm{Ct}$. The level of expression of type I and type II collagen was calculated as $2^{\Delta \mathrm{Ct}}$. Each sample was assessed at least in duplicate for each gene of interest.

\section{Biochemical analysis}

HAC pellets cultured in chondrogenic medium for two weeks were digested with protease $\mathrm{K}(0.5 \mathrm{ml}$ of $1 \mathrm{mg} / \mathrm{ml}$ protease $\mathrm{K}$ in $50 \mathrm{mM}$ Tris with $1 \mathrm{mM}$ EDTA, $1 \mathrm{mM}$ iodoacetamide, and $10 \mu \mathrm{g} / \mathrm{ml}$ pepstatin-A) for 15 hours at $56^{\circ} \mathrm{C}$ (Hollander et al., 1994). The glycosaminoglycan (GAG) content was measured spectrophotometrically using dimethylmethylene blue (Farndale et al., 1986), with chondroitin sulphate as a standard, and normalized to the DNA amount, measured spectrofluorometrically using the CyQUANT Kit (Molecular Probes, Eugene, OR, USA), with calf thymus DNA as a standard. GAG contents are reported as $\mu \mathrm{g}$ GAG / $\mu \mathrm{g}$ DNA.
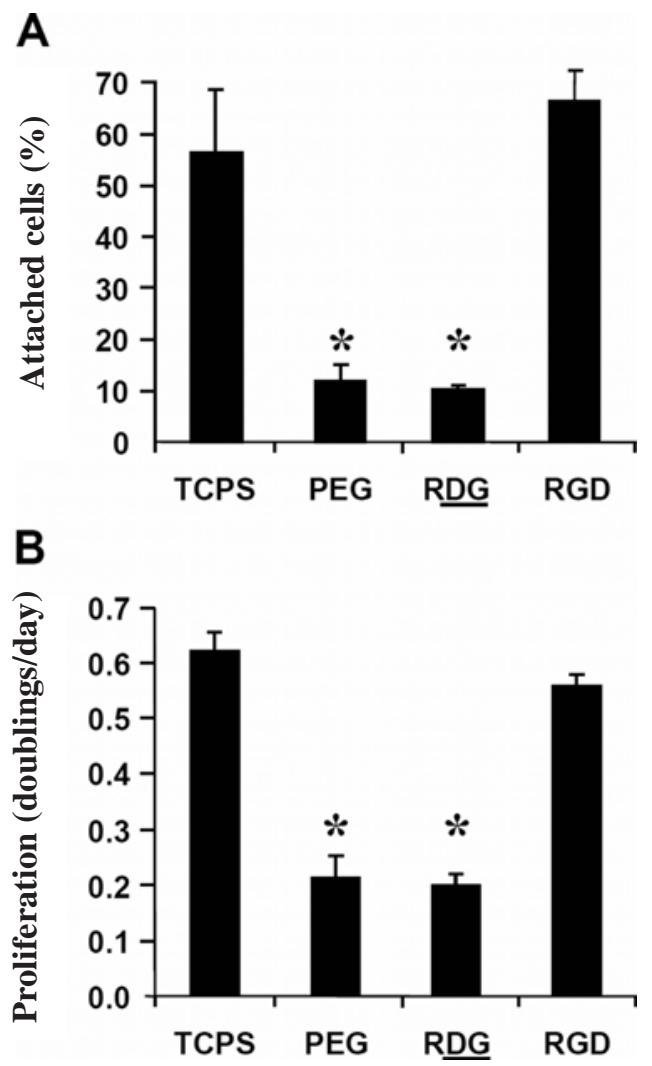

Fig. 3: Attachment and proliferation of adult human articular chondrocytes (HAC) on tissue culture polystyrene (TCPS), RGD-functionalized PLL-g-PEG (RGD), RDG-functionalized PLL-g-PEG (RDG, scrambled sequence) and non-functionalized PLL- $g$ PEG (PEG). RGD peptide surface density was $1.6 \mathrm{pmol} /$ $\mathrm{cm}^{2}$. A 24 hours after seeding in expansion medium, the number of attached cells was determined indirectly by counting the floating cells in the supernatant (alive and dead) and subtracting them from the number of inoculated cells. The attachment is expressed as percentage of the number of initially seeded cells. The values for attachment were: $56 \pm 12 \%$ (TCPS), $12 \pm 3 \%$ (PEG), $13 \pm 1 \%$ (RDG) and $66 \pm 6 \%$ (RGD). B The proliferation rate of HAC is expressed as $\mathrm{N}$ doublings per day (during the two expansion steps of 7 days duration each). The values for proliferation were: $0.62 \pm 0.03$ (TCPS), $0.21 \pm 0.04$ (PEG), $0.20 \pm 0.02$ (RDG) and $0.56 \pm 0.02$ (RGD). The asterisk indicates a significant difference vs. TCPS (two experimental replicates for HAC from 3 donors; $\mathrm{n}=6 ; p \leq 0.009$, Tukey HSD test).

\section{Histological and immunohistochemical analysis}

Cell pellets cultured in chondrogenic medium were fixed in $4 \%$ formalin for $24 \mathrm{~h}$, embedded in paraffin, crosssectioned ( $5 \mu \mathrm{m}$ thick), and stained with Safranin O for sulphated glycosaminoglycan (GAG) (Barbero et al., 2003). Sections were also processed for immunohistochemistry to visualize type II collagen (IIII6B3, Hybridoma Bank, University of Iowa, Iowa City, IA, USA), as previously described (Grogan et al., 2003).

\section{Statistical analysis}

Statistical evaluation was performed using SPSS software (version 15.0, SPSS Schweiz AG, Zürich, Switzerland). 
TCPS
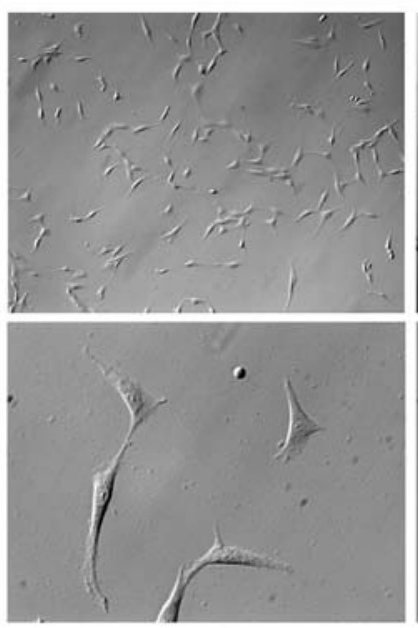

PEG
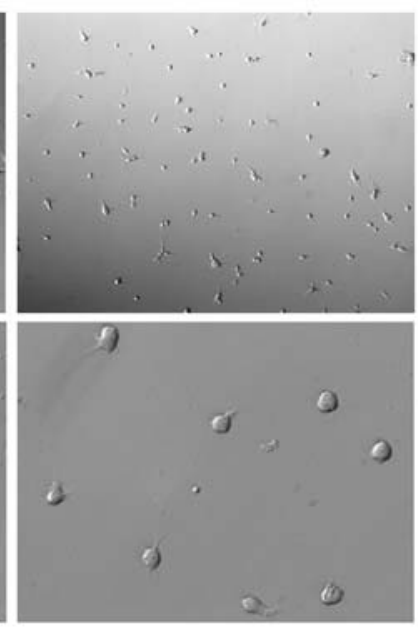

$\mathrm{RDG}$
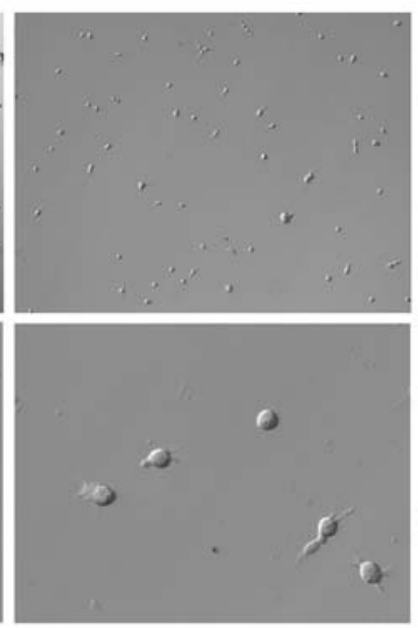

RGD
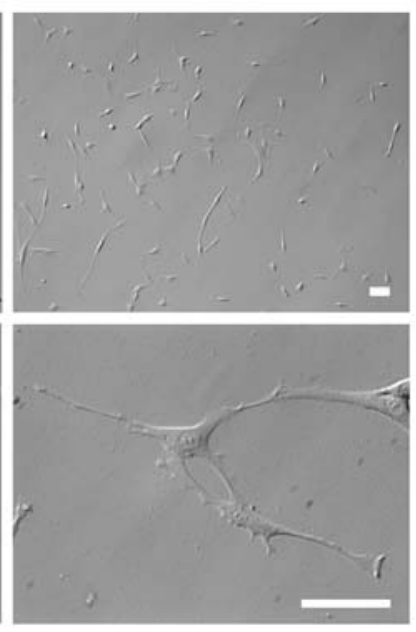

Fig. 4: Phase contrast images of adult human articular chondrocytes (HAC) in expansion medium, 24 hours after seeding onto either tissue culture polystyrene (TCPS), non-functionalized PLL- $g$-PEG (PEG), the scrambled sequence RDG-functionalized PLL-g-PEG (RDG) or the RGD-functionalized PLL- $g$ - PEG (RGD). RGD and RDG peptide surface density was 1.6 and $1.7 \mathrm{pmol} / \mathrm{cm}^{2}$ respectively. Scale bars correspond to $100 \mu \mathrm{m}$.

All mean values are presented as standard error $( \pm \mathrm{SE})$. Differences between the surfaces TCPS, RGD, RDG and $P E G$ were assessed using complying statistical tests as indicated at each result. The level of significance was set to $p<0.05$.

\section{Results}

\section{Substrate characterization}

Peptide ligand density and protein adsorption were determined using NMR and optical wave guided light spectroscopy. The RGD modified surface was determined to have a PLL-g-PEG/PEG-RGD-polymer concentration of $143 \mathrm{ng} / \mathrm{cm}^{2}$ (see Table 1). This concentration was sufficient to render the surface resistant to protein adsorption $\left(<5 \mathrm{ng} / \mathrm{cm}^{2}\right)$ and implies that the bio-ligand RGD was presented at a density of $1.6 \mathrm{pmol} / \mathrm{cm}^{2}$ (Table 1). Similar results were obtained for the control peptide $R \underline{D G}$.

\section{HAC attachment, spreading kinetics and proliferation}

To test whether an RGD-peptide containing ligand is sufficient to mediate attachment and proliferation, HAC were seeded in expansion medium onto $R G D$, while TCPS was employed as a standard control. Routine phase contrast microscopy observation revealed that, as early as 10 min after seeding, HAC on RGD started to spread, while on TCPS they still showed a more round morphology (reproducible for all donors). To quantify this observation, the spreading of HAC from donor $\mathrm{C}$ was captured every 2 minutes, starting 5 minutes after seeding onto the corresponding surface (see Fig. 2). Indeed, on RGD the maximal spreading speed $\left(88 \pm 6 \mu \mathrm{m}^{2} / \mathrm{min}\right)$ was 1.9 -fold higher as compared to that on TCPS ( $46 \pm 4 \mu \mathrm{m}^{2} / \mathrm{min} ; p<$ $10^{-5}$; U-test Mann-Whitney, two tailed). Despite this initial difference, HAC attachment (24 h after seeding) on RGD did not significantly differ from that on TCPS. However, attachment was drastically lower on the control substrates $P E G$ (no peptide ligand; 4.7-fold) and RDG (scrambled sequence; 5.6-fold) (Tukey HSD test: $p<0.009$; see Fig. $3 \mathrm{~A}$ ). Phase contrast images confirmed attachment of HAC on TCPS and $R G D$, revealed a homogenous distribution and a spread, fibroblastic cell morphology (Fig. 4). In contrast, on $P E G$ and $R \underline{D G}$, HAC appeared to attach to a very limited extent, and predominantly remained in suspension as clusters.

Throughout 14 days of expansion, the proliferation rate of HAC on RGD did not differ from that measured on TCPS, while it was lower on the bio-inactive surfaces PEG (2.9-fold) and RDG (3.1-fold) ( $p<0.004$; Tukey HSD test; see Fig. 3 B). As $P E G$ and $R G D$ only supported low HAC proliferation, these control conditions were not considered for further analysis.

\section{HAC morphology and motility during cell expansion}

To see, whether there are differences in morphology of HAC during expansion (passage 2; 3 days after seeding) on either RGD or TCPS, fluorescence images of fixed, Factin labelled cells were analysed. While the actin stress fibres are an indicator for cytoskeletal tension, the cytoplasmic staining simplifies the image analysis (i.e. automatic cell outlines). The average footprint area (see Fig. 5 A) of HAC growing on TCPS was $19 \%$ higher than on $R G D$ (Two-way analysis of variance (Anova): $p=$ 0.014 ), while the average perimeter of HAC on TCPS $(330 \pm 22 \mu \mathrm{m})$ was consistently lower than on $R G D(424 \pm 27$ $\mu \mathrm{m}$; Two-way Anova: $p<10^{-7}$ ). As a consequence, the average shape factor $\phi_{\mathrm{A}}$ on $R G D$ (see Fig. $5 \mathrm{~A}$ ) was 2.0fold lower (Two-way Anova: $p<10^{-7}$ ) as compared to that of HAC expanded on TCPS. This morphological difference also became apparent by directly comparing the CLSM images (see Fig. 5 C\&D). On both TCPS and RGD, a homogenous fluorescence signal could be seen throughout an entire HAC as actin appeared to be mostly organized 

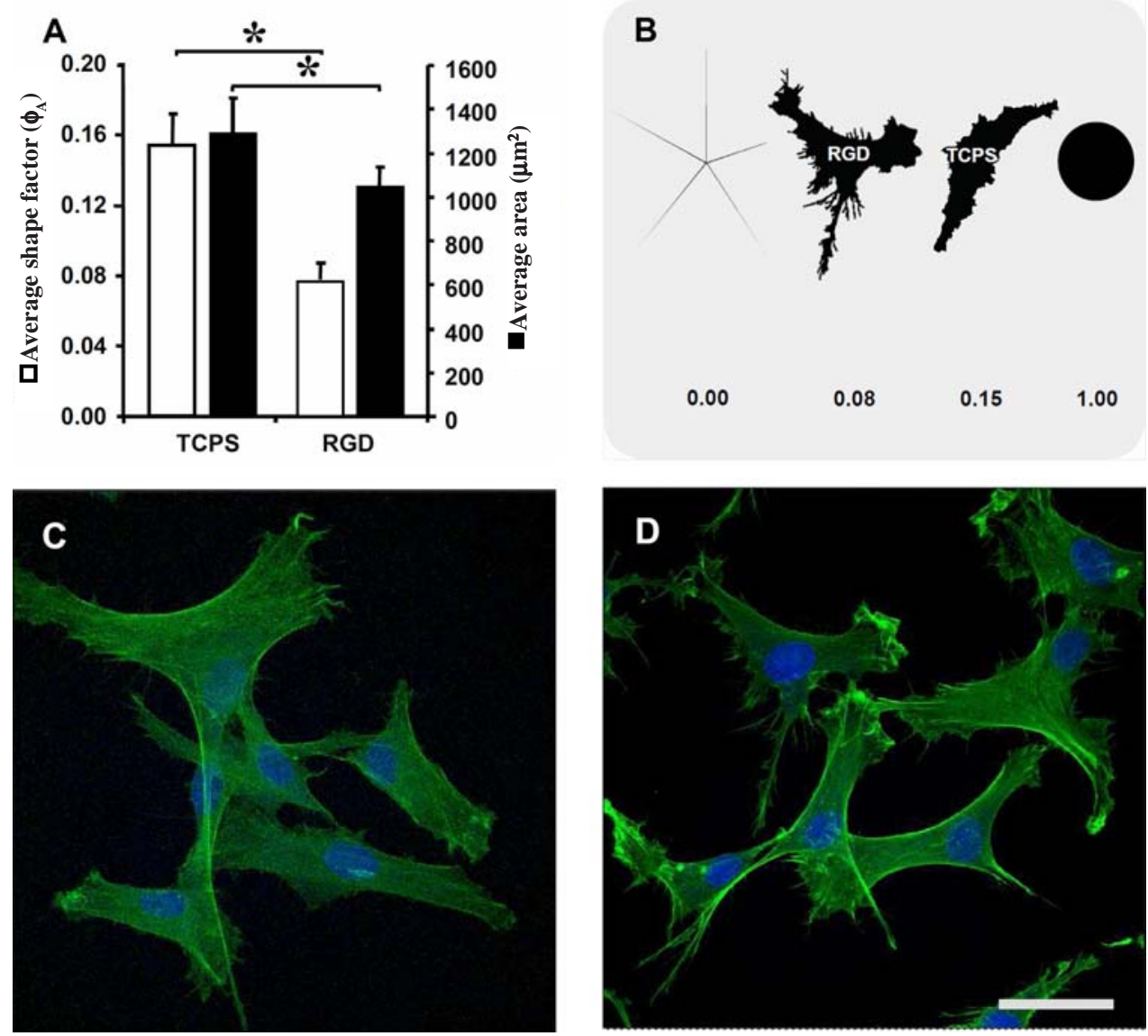

Fig. 5: Morphology of adult human articular chondrocytes (HAC, passage 2) in expansion medium, 3 days after seeding onto either tissue culture polystyrene (TCPS) or RGD-functionalized PLL-g-PEG (RGD). The graph in A represents the average shape factor $\phi \mathrm{A}$ (white bars) and the average footprint area in $\mu \mathrm{m}^{2}$ (black bars) of HAC on the corresponding substrate. The asterisk indicates a significant difference (On each surface, 30 HAC from each of three different donors were measured; $\mathrm{n}=90 ; p<0.0014$, two-way ANOVA). The cartoon in B visualizes shape factor values which can range from zero for starfish-shaped cells to one for perfectly round shaped cells. Representative confocal laser scanning microscopy images of HAC on C TCPS and D RGD show actin stress fibers (green) and nuclei (blue). Note the filopodia-like structures, which appear more frequent on RGD. Scale bar corresponds to $20 \mu \mathrm{m}$.

into fine filamentous structures. Only rarely, thicker actin bundles, as they are typical for stress fibres, were evident. Regions of highest actin-signal intensities were located at the lamellipodia, as well as at the filopodia-like extensions. These extensions were the most distinctive morphological feature of HAC adherently growing on $R G D$ as compared to TCPS. Time-lapse phase contrast microscopy was employed to analyze, whether these filopodia-like structures are associated with increased motility of HAC. However, on $R G D$ cell motility $(3.8 \pm 0.2 \mathrm{~nm} / \mathrm{s}, \mathrm{n}=230)$ was approximately $20 \%$ lower than on TCPS $(4.7 \pm 0.2 \mathrm{~nm} /$ $\mathrm{s}, \mathrm{n}=209 ; p=0.002$; Student's $t$-test, two tailed). The direction of HAC migration was judged by the distribution of centred cell trajectories and found to be isotropic on both $R G D$ and TCPS (data not shown).

\section{HAC de-differentiation during cell expansion}

At the end of expansion (14 days, passage 2) in monolayer, the de-differentiation state of HAC on either RGD or TCPS was compared using mRNA expression analysis. As a key chondrogenic marker, type II collagen mRNA expression of HAC on $R G D$ was 4.9 -fold higher as compared to that on TCPS ( $p<0.04$; U-test Mann-Whitney, two tailed),

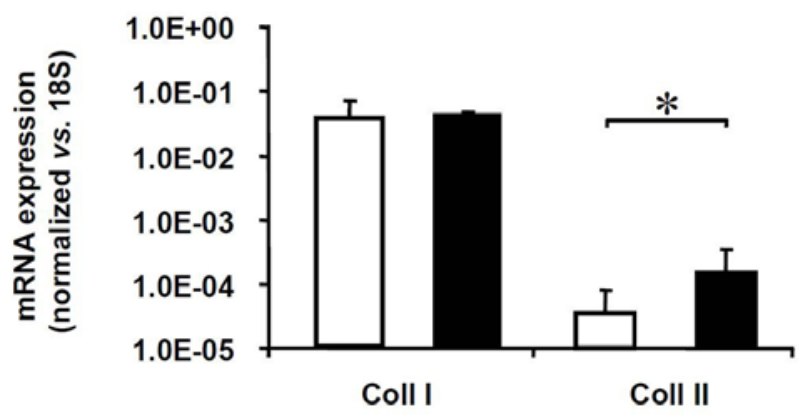

Fig. 6: Type I (Coll I) and II (Coll II) collagen mRNA expression levels (delta CT, housekeeping gene: $18 \mathrm{~S}$ ) of adult human articular chondrocytes (HAC) after 14 days of expansion on either tissue culture polystyrene (TCPS, white bars) or RGD-functionalized PLL-g-PEG (RGD, black bars). RGD peptide surface density was $1.6 \mathrm{pmol} / \mathrm{cm}^{2}$. The asterisk indicates a significant difference (two experimental replicates for HAC from three different donors were performed; $\mathrm{n}=6 ; p<0.05$, U-test Mann-Whitney, two tailed). 
Glycosaminoglycans

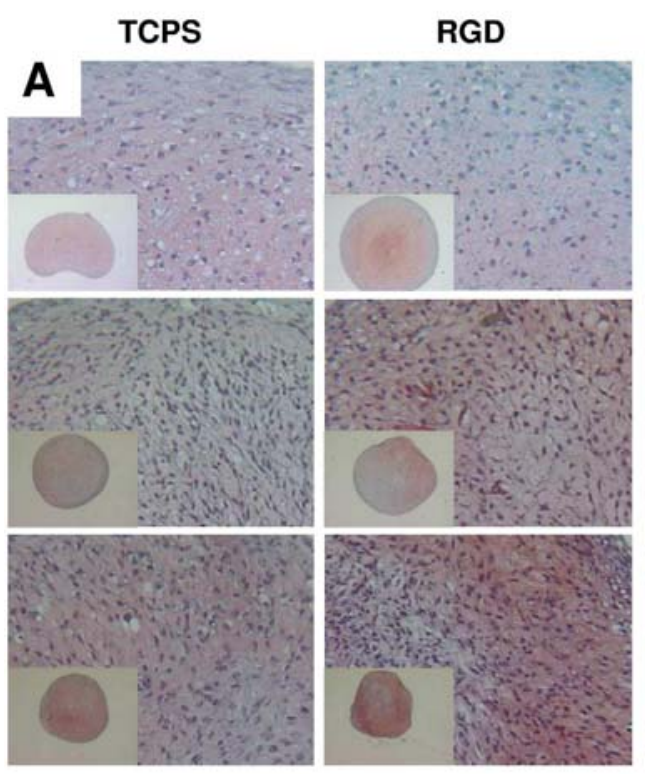

C

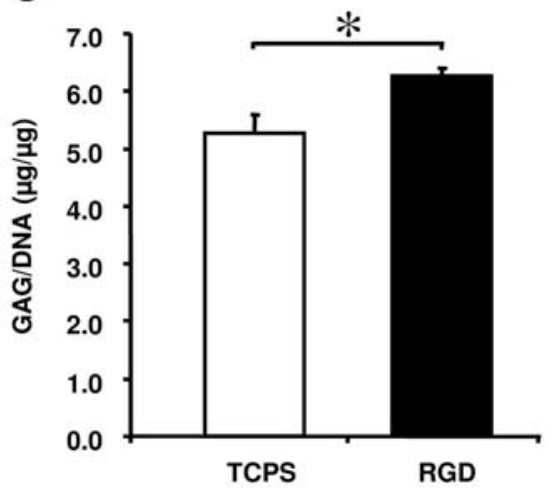

\section{Collagen II}

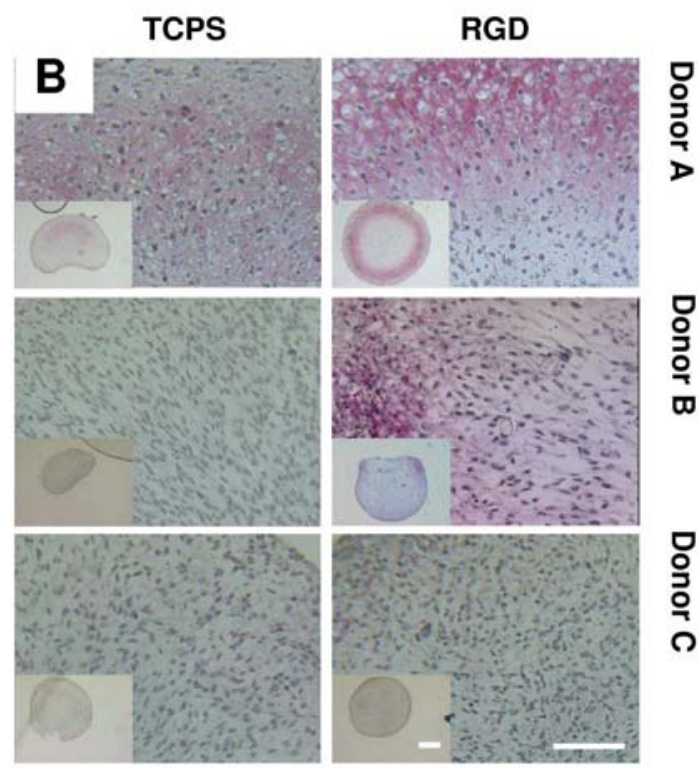

D

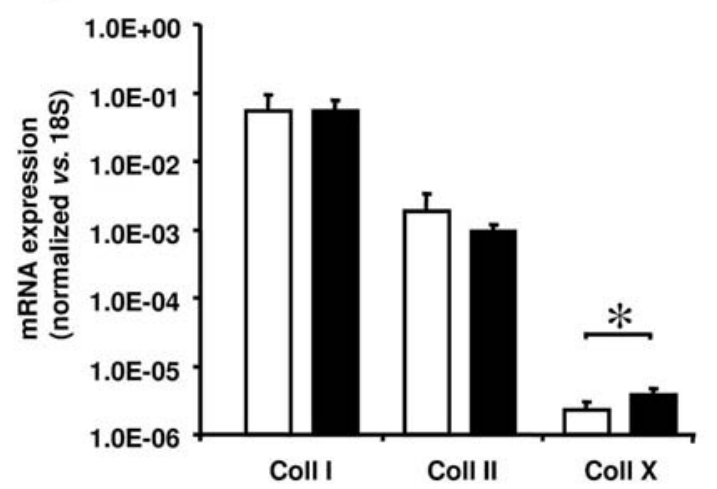

Fig. 7: Re-differentiation of expanded human articular chondrocytes (HAC). The re-differentiation capacity of HAC expanded on either tissue culture polystyrene (TCPS) or RGD-functionalized PLL-g-PEG (RGD, RGD peptide surface density: $1.6 \mathrm{pmol} / \mathrm{cm}^{2}$ ) was assessed in pellet culture (for 14 days in chondrogenic medium). A: Pellet sections stained red for glycosaminoglycans with Safranin O. B: Pellet sections immunohistochemically labelled red for collagen II. Representative sections are displayed for each donor and surface type. As an overview the insets present entire pellet sections. Scale bars correspond to $50 \mu \mathrm{m}$ for large panels and to $500 \mu \mathrm{m}$ for the small insets. C: Graph for accumulated GAG/DNA in pellets. The asterisk indicates a significant difference between TCPS and RGD ( $\mathrm{n}=6, p=0.016$, U-test Mann-Whitney, two tailed). D Type I (Coll I), II (Coll II) and X (Coll X) collagen mRNA expression levels in pellets generated from HAC expanded on TCPS (white bars) or RGD (black bars). All values are normalized vs. the house keeping gene $18 \mathrm{~S}$, with error bars representing the standard error $(\mathrm{n}=6)$.

while the level for the fibrous tissue marker, type I collagen mRNA, remained similar (see Fig. 6).

\section{HAC re-differentiation in pellet culture}

The re-differentiation capacity of monolayer expanded HAC was assessed using a standard chondrogenic assay, in which pellets were generated with HAC expanded on either TCPS or RGD and cultured in chondrogenic medium for two weeks. Chondrogenesis was assessed based on mRNA expression and formation of cartilaginous tissue (biochemistry, histology and immunohistochemistry, see Fig. 7).
The up-regulation of type II collagen mRNA during the expansion of HAC on RGD was not maintained in the subsequent pellet culture. Only for the hypertrophic marker, type X collagen mRNA, a statistically significant ( $p<0.004$; U-test Mann-Whitney, two tailed) but rather limited up-regulation (1.7-fold) was found.

HAC expanded on $R G D$ generated pellets with $15 \%$ higher GAG content accumulation $(6.3 \pm 0.2 \mu \mathrm{g} / \mu \mathrm{g} ; p=$ 0.016, U-test Mann-Whitney, two tailed) than HAC expanded on TCPS $(5.3 \pm 0.5 \mu \mathrm{g} / \mu \mathrm{g})$. Additionally, sections of pellets from $R G D$ expanded HAC stained slightly more intense for GAG (Safranin O staining) and type II collagen (Fig. 7). 


\section{Discussion}

In this in vitro study, we exploited the advantage of the PLL- $g$-PEG/PEG-RGD (RGD) model to restrict the interaction of HAC with the culture substrate exclusively through the cell adhesion ligand RGD, even in the presence of serum. As compared to TCPS, RGD allowed for comparable attachment, proliferation and migration while supporting faster initial spreading but smaller final spreading area. The higher expression of type II collagen mRNA during monolayer culture on $R G D$ coincided with limited, yet consistently enhanced GAG deposition in the subsequent pellet culture. However, type II collagen gene expression was not higher, neither on the mRNA nor on the protein level in pellets generated from HAC expanded on RGD.

The amount of serum proteins measured on the PLL$g$-PEG modified substrates was very low and fell below the detection limit range reported for the optical waveguide light mode spectroscopy technique. (Pasche et al., 2003) This protein resistant effect can be attributed to the architecture of the PEG brush. (Heuberger et al., 2005) Indeed, on $P E G$ and $R \underline{D G}$ (scrambled cell adhesion sequence), HAC attached to a very limited extent and mostly remained suspended in the culture medium as clusters. The fact that on these bio-inactive surfaces cell attachment was not completely abolished could be explained by small local defects in the PLL-g-PEG or PLL$g$-PEG/PEG- $R \underline{D} G$ - layer, which likely permitted limited serum adsorption. These defects appeared to occur at a low frequency and merely allowed for cell anchoring but never for cell spreading. Only where PLL-g-PEG was modified with the cell adhesion ligand RGD, HAC attached and spread comparably to the way they do on TCPS. As $R \underline{D G}$ was not able to mediate the same effects, we assume that the effects observed in this study are specifically mediated by the bioligand RGD. Thus, the PLL- $g$-PEG/ PEG-RGD culture surface effectively allows for HAC/ substrate interactions exclusively through RGD ligands, thereby circumventing the formation of a complex proteinaceous interface, even in presence of serum containing medium.

Early after seeding, HAC spreading always appeared more advanced on $R G D$ than on TCPS. This observation was confirmed by measuring an almost two fold higher initial spreading rate on $R G D$ as compared to that on TCPS. Although cell spreading ultimately reaches a plateau level, during the initial spreading (18 min), HAC only assumed approximately $40 \%$ of the maximal spreading area (as reported in Fig. 5A). However, this period was sufficient to determine the maximal slope based on a $3^{\text {rd }}$ order polynomial fit which well fitted the spreading kinetic data points.

Since the spreading area was smaller on $R G D$ than on TCPS, the higher spreading rate on $R G D$ was likely not due to a higher cell adhesion ligand density, but rather to a sterically more direct mode of interaction of HAC integrins with the surface bound RGD. This is consistent with the fact that the RGD ligand is displayed in front of an otherwise inert environment (PEG brush border), as opposed to the various different orientations (Talbot et al.,
2000) of randomly adsorbed serum proteins, where ligands can remain encrypted (e.g., within the FnIII modules of folded fibronectin (Vogel, 2006)). Although cells have the ability to access these cryptic domains by applying cytoskeletal tension, (Baneyx et al., 2002) this active remodelling process of the protein adlayer would require longer time. Whether the faster spreading on $R G D$ is really due to a more direct mode of interaction, would however require further investigations, beyond the scope of this study.

HAC cultured on RGD and on TCPS attached and proliferated to an extent as previously reported for standard HAC culture (Barbero et al., 2004; Cui et al., 2003). A drastically reduced attachment on the bio-inactive surfaces (PEG \& $R \underline{D G}$ ) coincided with a decreased proliferation rate, which is in line with findings for human dermal fibroblasts (Schuler et al., 2006a). Chondrocytes adhering to cartilage ECM-proteins highly express $\beta 1$ integrins and knocking out these integrins in a mouse model led to decreased chondrocyte proliferation due to impaired G1/ $\mathrm{S}$ transition and cytokinesis (Aszodi et al., 2003). RGD partially activates $\alpha 5 \beta 1$ (Redick et al., 2000; Ochsenhirt et al., 2006) but primarily $\alpha v \beta 3$ integrin receptor (Petrie et al., 2006) and thus seems likely to have stimulated proliferation through integrin activated signalling.

HAC cultured on RGD or TCPS assumed an elongated morphology (see Fig. 5), as confirmed by quantification of the shape factor $\left(\phi_{\mathrm{A}}\right)$, which did not exceed the value of 0.2 . The lower shape factor on RGD than on TCPS does not reflect further elongation but can be attributed to the protrusive extensions which mainly contributed to the increased perimeter. Such distinctive morphological features remind of filopodia which have been reported to occur at the leading edge of motile cells (Mitchison and Cramer, 1996). However, HAC motility on TCPS was found to be in the same range as reported for rabbit chondrocytes (Maniwa et al., 2001), and lower on RGD, where filopodia-like structures were primarily observed.

Both the lower motility and the higher type II collagen mRNA expression of HAC expanded on $R G D$, as compared to TCPS, could be related to the reduced cell spreading area. In fact, cell spreading is associated with ROCK-mediated cytoskeletal tension (McBeath et al., 2004) and is known to block chondrogenesis in mouse mesenchymal limb bud cells by inhibiting the expression of the transcription factor Sox9 (Woods et al., 2005). A reason for the reduced HAC spreading on $R G D$ could be its lower bioactivity as compared to native ligands, where complementary or modulatory domains are present (Petrie et al., 2006). In fact, FN, which readily adsorbs to TCPS (Kowalczynska et al., 2009), contains the synergistic binding site PHSRN on $9^{\text {th }}$ type III repeat (FIII9) in addition to the RGD motif in the $10^{\text {th }}$ type III repeat (FIII10). RGD is considered to be a poor FN mimic (Petrie et al., 2006) as on its own it is not sufficient to fully activate $\alpha 5 \beta 1$ integrin but requires the synergy with PHSRN (Mardon and Grant, 1994; Kreiner et al., 2008). Disturbing the interdomain interaction of the FIII9-10 pair was reported to result in reduced spreading of baby hamster kidney cells and human endometrial stromal fibroblasts (Grant et al., 1997). 
The higher expression of the chondrogenic marker gene type II collagen during expansion of HAC on RGD resulted in consistent but rather marginal improvements of chondrogenesis during pellet culture, as evidenced by the slightly higher accumulation of GAG/DNA, staining intensity for GAG and type II collagen expression in the formed tissues. It is possible that enzymatic disruption of HAC adhesion to RGD (for establishing pellet cultures) degraded important cell surface proteins (Majd et al., 2009) and partially reset the instructive signal to HAC. In this regard, future investigations should circumvent the need for such a harvesting step. As an example, HAC could be expanded on an RGD-ligand restricted scaffold and directly differentiated in the same material. Still, the presentation of RGD might have to be transient (during expansion), since modifying alginate with an RGD-ligand was previously found to inhibit BMSC chondrogenesis (Connelly et al., 2007; Connelly et al., 2008).

Beyond allowing control over the mode of cell interaction with a biomaterial interface, small ECMfragments also offer the opportunity to modify/tune the bioactivity of native proteins. The results of this study suggest that the limited bioactivity of $R G D$ better supports the chondrogenic phenotype of proliferating HAC as compared to a complex proteinaceous adlayer containing native FN (TCPS). Thus, it would be intriguing to test whether tuning RGD-restricted HAC/substrate interactions could yield still higher type II collagen expression (as e.g., on $P E G$ ), while preserving its effect to promote proliferation (as e.g., on $R G D$ ). Approaches to tune HAC/ RGD-restricted substrate interaction could involve changing the sequence of the peptide ligand (Kato et al., 2006), controlling its spatial array (Maheshwari et al., 2000) or coupling it to substrates with different mechanical compliance than stiff TCPS (Engler et al., 2006).

\section{Conclusion and Outlook}

In summary, forcing HAC-substrate interactions through $R G D$ peptides not only mediated instantaneous cell attachment but also supported cell migration, proliferation and maintenance of the post-expansion cartilage forming capacity. Assisting these processes with inductive/ instructive biomaterials may be essential for improving in situ cartilage regeneration, stimulated by microfracturing (Richter, 2009; McNickle et al., 2008). In microfracturing, the subchondral bone plate is penetrated by small perforations which allow the recruitment/infiltration of mesenchymal stromal cells (MSC) from the bone marrow (Kramer et al., 2006). MSC have the potential to differentiate chondrogenically (Yoo et al., 1998), but due to their low numbers they first need to proliferate in situ in order to possibly improve the final outcome (Richter, 2009). Thus, an RGD-ligand restricted biomaterial interface could be a valuable tool to assist microfracture stimulated cartilage regeneration.

\section{Acknowledgements}

We wish to thank Rosmarie Sütterlin for her help with the fluorescence microscopy and Francine Wolf for her help with the histological analysis.

\section{References}

Aszodi A, Hunziker EB, Brakebusch C, Fässler R (2003) Beta1 integrins regulate chondrocyte rotation, G1 progression, and cytokinesis. Genes Dev 17: 2465-2479.

Aulthouse A, Beck M, Griffey E, Sanford J, Arden K, Machado M, Horton W (1989) Expression of the human chondrocyte phenotype in vitro. In Vitro Cell Dev Biol Plant 25: 659-668.

Baneyx G, Baugh L, Vogel V (2002) Fibronectin extension and unfolding within cell matrix fibrils controlled by cytoskeletal tension. Proc Natl Acad Sci USA 99: 51395143.

Barbero A, Ploegert S, Heberer M, Martin I (2003) Plasticity of clonal populations of dedifferentiated adult human articular chondrocytes. Arthritis Rheum 48: 13151325 .

Barbero A, Grogan SP, Schafer D, Heberer M, MainilVarlet P (2004) Age related changes in human articular chondrocyte yield, proliferation and post-expansion chondrogenic capacity. Osteoarthritis Cartilage 12: 476484.

Barbero A, Grogan SP, Mainil-Varlet P, Martin I (2006) Expansion on specific substrates regulates the phenotype and differentiation capacity of human articular chondrocytes. J Cell Biochem 98: 1140-1149.

Benya PD, Shaffer JD (1982) Dedifferentiated chondrocytes reexpress the differentiated collagen phenotype when cultured in agarose gels. Cell 30: 215224.

Brittberg M (2008) Autologous chondrocyte implantation-Technique and long-term follow-up. Injury 39: 40-49.

Brodkin KR, Garcia AJ, Levenston ME (2004) Chondrocyte phenotypes on different extracellular matrix monolayers. Biomaterials 25: 5929-5938.

Connelly JT, Garcia AJ, Levenston ME (2008) Interactions between integrin ligand density and cytoskeletal integrity regulate BMSC chondrogenesis. J Cell Physiol 217: 145-154.

Connelly JT, Garcia AJ, Levenston ME (2007) Inhibition of in vitro chondrogenesis in RGD-modified three-dimensional alginate gels. Biomaterials 28: 10711083.

Cui YL, Qi AD, Liu WG, Wang XH, Wang H, Ma DM, Yao KD (2003) Biomimetic surface modification of poly(lactic acid) with chitosan and its effects on articular chondrocytes in vitro. Biomaterials 24: 3859-3868.

Darling EM, Athanasiou KA (2005) Rapid phenotypic changes in passaged articular chondrocyte subpopulations. J Orthopaed Res 23: 425-432.

Engler AJ, Sen S, Sweeney HL, Discher DE (2006) Matrix elasticity directs stem cell lineage specification. Cell 126: 677-689. 
Farndale RW, Buttle DJ, Barrett AJ (1986) Improved quantitation and discrimination of sulfated glycosaminoglycans by use of dimethylene blue. Biochim Biophys Acta 883: 173-177.

Franks W, Tosatti S, Heer F, Seif P, Textor M, Hierlemann A (2007) Patterned cell adhesion by selfassembled structures for use with a CMOS cell-based biosensor. Biosens Bioelectron 22: 1426-1433.

Garciadiego-Cázares D, Rosales C, Hatoh M, ChimalMonroy J (2004) Coordination of chondrocyte differentiation and joint formation by $\alpha 5 \beta 1$ integrin in the developing appendicular skeleton. Development 131: 4735-4742.

Grant RP, Spitzfaden C, Altroff H, Campbell ID, Mardon HJ (1997) Structural requirements for biological activity of the ninth and tenth FIII domains of human fibronectin. J Biol Chem 272: 6159-6166.

Grogan SP, Rieser F., Winkelmann V, Berardi S., Mainil-Varlet P (2003) Static, closed and scaffold-free bioreactor system that permits chondrogenesis in vitro. Osteoarthritis Cartilage 11: 403-411.

Hersel U, Dahmen C, Kessler H (2003) RGD modified polymers: Biomaterials for stimulated cell adhesion and beyond. Biomaterials 24: 4385-4415.

Heuberger M, Drobek T, Spencer N.D. (2005) Interaction forces and morphology of a protein-resistant poly(ethylene glycol) layer. Biophys J 88: 495-504.

Hollander AP, Heathfield TF, Webber C, Iwata YBR, Rorabeck A (1994) Increased damage to type II collagen in osteoarthritic articular cartilage detected by a new immunoassay. J Clin Invest 93: 1722-1732.

Horbett TA (1986) Techniques for protein adsorption studies. In: Techniques of Biocompatibility Testing II (Williams DF, ed). CRC Press, Boca Raton, pp 183-213.

Hsu SH, Chang SH, Yen HJ, Whu SW, Tsai CL, Chen DC (2006) Evaluation of biodegradable polyesters modified by type II collagen and Arg-Gly-Asp as tissue engineering scaffolding materials for cartilage regeneration. Artif Organs 30: 42-55.

Hsu S, Whu S, Hsieh S, Tsai C, Chen D, Tan T (2004) Evaluation of chitosan-alginate-hyaluronate complexes modified by an RGD-containing protein as tissueengineering scaffold for cartilage repair. Artif Organs 8: 693-703.

Hubbell JA (1999) Bioactive biomaterials. Curr Opin Biotechnol 10: 123-129.

Jakob M, Demarteau O, Schafer D, Hintermann B, Dick W, Heberer M (2001) Specific growth factors during the expansion and redifferentiation of adult human articular chondrocytes enhance chondrogenesis and cartilaginous tissue formation in vitro. J Cell Biochem 81: 368-377.

Jeschke B, Meyer Jr, Jonczyk A, Kessler H, Adamietz P, Meenen NM, Kantlehner M, Goepfert C, Nies B (2002) RGD-peptides for tissue engineering of articular cartilage. Biomaterials 23: 3455-3463.

Kato R, Kaga C, Kunimatsu M, Kobayashi T, Honda $\mathrm{H}$ (2006) Peptide array-based interaction assay of solidbound peptides and anchorage-dependant cells and its effectiveness in cell-adhesive peptide design. J Biosci Bioeng 101: 485-495.
Kino-Oka M, Yashiki S, Ota Y, Mushiaki Y, Sugawara K, Yamamoto T, Taya M (2005) Subculture of chondrocytes on a collagen type I-coated substrate with supressed cellular dedifferentiation. Tissue Eng 11: 597608.

Koenig AL, Gambillara V, Grainger DW (2003) Correlating fibronectin adsorption with endothelieal cell adhesion and signalling on polymer substrates. J Biomed Mater Res 64: 20-37.

Kowalczynska HM, Kolos R, Nowak-Wyrzykowska M, Dobkowski J, Elbaum D, Szczepankiewicz A, Kaminski J (2009) Atomic force microscopy evidence for conformational changes of fibronectin adsorbed on unmodified and sulfonated polystyrene surfaces. J Biomed Mater Res Part A 91A: 1239-1251.

Kramer J, Bohrnsen F, Lindner U, Behrens P, Schlenke P, Rohwedel J (2006) In vivo matrix-guided human mesenchymal stem cells. Cell Mol Life Sci 63: 616-626.

Kreiner M, Li Z, Beattie J, Kelly SM, Mardon HJ, van der Walle CF (2008) Self-assembling multimeric integrin alpha 5 beta 1 ligands for cell attachment and spreading. Protein Eng Des Sel 21: 553-560.

Maheshwari G, Brown G, Lauffenburger DA, Wells A, Griffith LG (2000) Cell adhesion and motility depend on nanoscale RGD clustering. J Cell Sci 113: 1677-1686.

Majd H, Wipff PJ, Buscemi L, Bueno M, Vonwil D, Quinn TM, Hinz B (2009) A novel method of dynamic culture surface expansion improves mesenchymal stem cell proliferation and phenotype. Stem Cells 27: 200-209.

Maniwa S, Ochi M, Motomura T, Nishikori T, Chen J, Naora H (2001) Effects of hyaluronic acid and basic fibroblast growth factor on motility of chondrocytes and synovial cells in culture. Acta Orthopaed Scand 72: 299303.

Mardon HJ, Grant KE (1994) The role of the 9th and 10th type-III domains of human fibronectin in celladhesion. FEBS Lett 340: 197-201.

Marlovits S, Hombauer M, Truppe M, Vecsei V, Schlegel W (2004) Changes in the ratio of type-I and typeII collagen expression during monolayer culture of human chondrocytes. J Bone Joint Surg Br 86-B: 286-295.

McBeath R, Pirone DM, Nelson CM, Bhadriraju K, Chen CS (2004) Cell shape, cytoskeletal tension, and RhoA regulate stem cell lineage commitment. Dev Cell 6: 483495.

McNickle AG, Provencher MT, Cole BJ (2008) Overview of existing cartilage repair technology. Sports Med Arthrosc. 16: 196-201.

Mitchison TJ, Cramer LP (1996) Actin-based cell motility and cell locomotion. Cell 84: 371-379.

Mrksich M (2002) What can surface chemistry do for cell biology? Curr Opin Chem Biol 6: 794-797.

Nakanishi K, Sakiyama T, Imamura K (2001) On the adsorption of proteins on solid surfaces, a common but very complicated phenomenon. J Biosci Bioeng 91: 233244.

Ochsenhirt SE, Kokkoli E, McCarthy JB, Tirrell M (2006) Effect of RGD secondary structure and the synergy site PHSRN on cell adhesion, spreading and specific integrin engagement. Biomaterials 27: 3863-3874. 
Pasche S, De Paul SM, Voros J, Spencer ND, Textor M (2003) Poly(L-lysine)-graft-poly(ethylene glycol) assembled monolayers on niobium oxide surfaces: A quantitative study of the influence of polymer interfacial architecture on resistance to protein adsorption by ToFSIMS and in situ OWLS. Langmuir 19: 9216-9225.

Pasche S, Voros J, Griesser HJ, Spencer ND, Textor M (2005) Effects of ionic strength and surface charge on protein adsorption at PEGylated surfaces. J Phys Chem B 109: 17545-17552.

Petrie TA, Capadona JR, Reyes CD, Garcia AJ (2006) Integrin specificity and enhanced cellular activities associated with surfaces presenting a recombinant fibronectin fragment compared to RGD supports. Biomaterials 27: 5459-5470.

Rasband WS (2009) Image J. U. S. National Institutes of Health, Bethesda, MD, USA.

Redick SD, Settles DL, Briscoe G, Erickson HP (2000) Defining fibronectin's cell adhesion synergy site by sitedirected mutagenesis. J Cell Biol 149: 521-527.

Richter W (2009) Mesenchymal stem cells and cartilage in situ regeneration. J Int Med 266: 390-405.

Ruoslahti E (1996) RGD and other recognition sequences for integrins. Ann Rev Cell Develop Biol 12: 697-715.

Schuler M, Owen GR, Hamilton DW, De Wilde M, Textor M, Brunette DM, Tosatti S (2006a) Biomimetic modification of titanium dental implant model surfaces using the RGDSP-peptide sequence: A cell morphology study. Biomaterials 27: 4003-4015.

Schuler M, Trentin D, Textor M, Tosatti SGP (2006b) Biomedical interfaces: titanium surface technology for implants and cell carriers. Nanomedicine 1: 449-463.

Schuler M, Hamilton DW, Kunzler TP, Sprecher CM, de Wild M, Brunette DM, Textor M, Tosatti SGP (2009a) Comparison of the response of cultured osteoblasts and osteoblasts outgrown from rat calvarial bone chips to nonfouling KRSR and FHRRIKA-peptide modified rough titanium surfaces. J Biomed Mater Res Part B-Appl Biomater 91B: 517-527.

Schuler M, Kunzler TP, de Wild M, Sprecher CM, Trentin D, Brunette DM, Textor M, Tosatti SGP (2009b) Fabrication of $\mathrm{TiO}_{2}$-coated epoxy replicas with identical dual-type surface topographies used in cell culture assays. J Biomed Mater Res Part A 88A: 12-22.

Scully SP, Lee JW, Ghert MA, i W (2001) The role of the extracellular matrix in articular chondrocyte regulation. Clin Orthopaed Rel Res 391: S72-S89.

Shakibei M, De Souza P, Merker H-J (1997) Integrin expression and collagen type II implicated in maintenance of chondrocyte shape in monolayer culture: An immunomorphological study. Cell Biol Int 21: 115-125.

Stockdale FE, Abbott J, Holtzer S, Holtzer H (1963) The loss of phenotypic traits by differentiated cells : II. Behavior of chondrocytes and their progeny in vitro. Dev Biol 7: 293-302.

Talbot J, Tarjus G, Van Tassel PR, Viot P (2000) From car parking to protein adsorption: an overview of sequential adsorption processes. Colloids Surf A: Physicochem Eng Asp 165: 287-324.
Tosatti S, Schwartz Z, Campbell C, Cochran DL, VandeVondele S, Hubbell JA, Denzer A, Simpson J, Wieland M, Lohmann CH, Textor M, Boyan BD (2004) RGD-containing peptide GCRGYGRGDSPG reduces enhancement of osteoblast differentiation by poly(Llysine)-graft-poly(ethylene glycol)-coated titanium surfaces. J Biomed Mater Res Part A 68A: 458-472.

Van der Kraan PM, Buma P, van Kuppevelt T, van Den Berg WB (2002) Interaction of chondrocytes, extracellular matrix and growth factors: relevance for articular cartilage tissue engineering. Osteoarthritis Cartilage 10: 631-637.

VandeVondele S, Vöros J, Hubbell JA (2003) RGDgrafted poly-L-lysine-graft-poly(ethylene glycol) copolymers block non-specific protein adsorption while promoting cell adhesion. Biotechnol Bioeng 82: 784-790.

Vogel V (2006) Mechanotransduction involving multimodular proteins: Converting force into biochemical signals. Ann Rev Biophys Biomol Struct 35: 459-488.

Woods A, Wang GY, Beier F (2005) RhoA/ROCK signaling regulates Sox 9 expression and actin organization during chondrogenesis. J Biol Chem 280: 11626-11634.

Yoo JU, Barthel TS, Nishimura K, Solchaga L, Caplan AI, Goldberg VM, Johnstone B (1998) The chondrogenic potential of human bone-marrow-derived mesenchymal progenitor cells. J Bone Joint Surg-Am 80A: 1745-1757.

\section{Discussion with Reviewers}

Reviewer I: Why do the authors believe that such a RGD centred approach should be specifically suited for microfractures (as outlined in the conclusion section).

Authors: Based on our findings and the review by Richter et al. (2010), we argue that an RGD peptide-ligand could be useful as tool in augmenting the initial low number of potential chondroprogenitor cells, present immediately after microfracturing. The RGD peptide ligand should be viewed as one of the aspects relevant in designing biomaterials for matrix assisted cartilage repair, since the success of such an approach will also likely depend on other key factors such as material composition, architecture, mechanical properties and incorporated biological signals.

Reviewer I: Which type of biomaterial the authors feel could be the basis for the suggested use in microfracture treatment (foil? flowable?)?

Authors: We imagine that the material should have an architecture that allows for blood/bone marrow influx into the defect and subsequent stabilization of the formed clot. This could possibly be supported by a solid, highly interconnected, porous or fibrous scaffold that fills the defect void entirely. Foils which cover the defect, may serve as a physical barrier and prevent cell loss, but as 2D structures provide a limited surface area to place supportive/instructive motifs available for interaction with cells. Flowables that can be gelled or/solidified in situ and which are compatible with blood/bone-marrow influx into the defect, could also be seen as a basis for a matrix assisted microfracturing treatment. 
Reviewer III: Was the same batch of serum used for all experiments? This is important, as there could be differences in how the cells bind to the TCPS plates.

Authors: All experiments were performed with the same batch of serum. To avoid the lot to lot variation influences. Generally, we reserve bigger amounts of serum and evaluate it in in-house cell culture tests before buying larger amounts of the same lot (reserve serum testing option provided by Invitrogen/ Gibco).

Reviewer III: Have any long-term cultures been carried out? - How would the cells respond? It would be interesting to obtain data for long term cultures, as if RGD cultured cells were to be used for future clinical applications then it is very probable that the cells would be in culture for longer than a 2 week period in order to obtain sufficient cell numbers.

Authors: HAC have not been cultured longer than for 14 days. In this study, HAC have been expanded in classic monolayer culture, which requires that the cells are passaged when reaching subconfluency. As this is associated with de-differentiation, we generally do not exceed passage 3 in order to preserve their redifferentiation capacity. In a microfracturing scenario the chondroprogenitor cells would consist of MSC. In this regard, future studies should address the applicability of the RGD peptide-ligand with the latter cell type and also test longer culture times by starting at lower initial cell densities.
Reviewer III: A higher Collagen type X mRNA expression was observed in the pellets from cultures grown on the RGD co-polymer. However, if these cells were to be used for clinical application wouldn't it be more desirable that they terminally differentiated at a later stage?

Authors: Terminal differentiation would be desired at the osteochondral interface but not in mature articular cartilage of higher zonal origin. Thus, this is not solely a question of time but also of spatial position of the cells within the tissue/defect. Independent from this, type $\mathrm{X}$ collagen expression remained at very low levels even in pellets generated by RGD-expanded HAC. Moreover, in a previous unpublished study we failed to detect type $\mathrm{X}$ collagen $(\mathrm{CX})$ protein even in the HAC-based pellets where appreciable amounts of CX mRNA were quantified by RTPCR.

Reviewer IV: What response do the authors expect for other types of cells apart from chondrocytes? What was so particular about chondrocytes? How might these results be related?

Authors: RGD-grafted PLL-g-PEG has been assessed for its effect on attachment, morphology and proliferation of different cells including human fibroblasts and epithelial cells as well as rat osteoblasts, and cardiomyocytes (VandeVondele et al., 2003; Franks et al., 2007; Schuler et al., 2009a, text references). While generally, the RGDpeptide ligand was found to promote cell attachment and proliferation, its influence on differentiation has to be addressed for each cell type individually. 